\title{
Long-Term Changes in the Diurnal Precipitation Cycles in Japan for 106 Years (1898-2003)
}

\author{
Fumiaki FUJIBE, Nobuo YAMAZAKI \\ Meteorological Research Institute, Tsukuba, Japan \\ and \\ Kenji KOBAYASHI \\ Observations Department, Japan Meteorological Agency, Tokyo, Japan
}

(Manuscript received 5 September 2005, in final form 30 November 2005)

\begin{abstract}
Changes in the diurnal variation patterns of precipitation were analyzed using four-hourly data for 106 years (1898-2003) at 46 stations in Japan. On the annual and areal average, precipitation amount has a relative increasing trend in the early morning (02-06 JST) and a decreasing trend in the afternoon (14-18 JST), each with a rate of about $5 \%$ per century. These changes reflect those of intense precipitation $(\gtrsim 10 \mathrm{~mm} / 4 \mathrm{~h})$ in spring and summer, while precipitation amount in autumn and winter shows different changes of diurnal variation patterns. Changes of diurnal cycles of weak precipitation $(<3 \mathrm{~mm} / 4 \mathrm{~h})$ are generally small, with a slight relative increase in 06-14 JST, and a decrease in 14-18 JST.
\end{abstract}

\section{Introduction}

Diurnal variation of precipitation has been extensively studied in the world (e.g., Dai 2001; Tsakraklides and Evans 2003; Hirose and Nakamura 2005). In Japan, diurnal variation of warm season precipitation is characterized by an afternoon maximum dominant for localized precipitation in the inland, and a morning maximum prevailing in coastal areas and for widespread precipitation, with an exceptional midday maximum over the Nansei (Southwest) Islands (Fujibe 1988; Oki and Musiake 1994; Misumi 1999). The diurnal variation pattern depends also on the duration and

Corresponding author: Fumiaki Fujibe, Meteorological Research Institute, Tsukuba 305-0052, Japan.

E-mail: ffujibe@mri-jma.go.jp

(C) 2006, Meteorological Society of Japan intensity of precipitation, as well as on seasons (Tagami 1990; Fujibe 1999).

There is some evidence of long-term changes in the diurnal precipitation cycle. For example, the intensification of the urban heat island is believed to enhance convective precipitation most effectively in the afternoon (Changnon ed. 1981; Landsberg 1981; Fujibe 1998). On a larger scale, the alteration of wet and dry periods and/or the ENSO cycle can cause interannual changes in the diurnal precipitation cycles (Shinoda et al. 1999; Hu 2003; Mohr 2004). Jung et al. (2001) described the multi-decadal variation of diurnal precipitation pattern at Seoul using traditional Korean raingauge data since the 18th century. Dai (1999) described the seasonal and regional features of long-term trends of diurnal precipitation cycles in the United States for 31 years. However, studies on the climatic change of diurnal precipitation cycles have been very few, due to scarcity of 
data having time resolution less than a day, and sufficient temporal coverage.

Until a few years ago, digitalized data usable for analysis of diurnal precipitation variation in Japan were limited to visual records from 1961 and raingauge records from 1976. Fujibe et al. $(2005 \mathrm{a}, \mathrm{b})$ studied the trends of precipitation and thunder frequencies using visual data at observatories of the Japan Meteorological Agency (JMA). They found relative decrease of daytime precipitation frequency at a rate of the order of $1 \%$ per decade over all the regions, and decrease of thunder frequency in the afternoon (15 JST) of summer at a rate of about $10 \%$ per decade.

Recently, precipitation data at JMA observatories were digitalized for the full period of operation. Fujibe et al. (2005c) analyzed the trends of precipitation intensity using fourhourly data at 46 stations for the period 18982003. By defining ten intensity categories, they found an increasing trend of intense precipitation, and a decrease of weak precipitation, at a rate of $20-30 \%$ per century. In the present study, this dataset is used to find the longterm changes of diurnal variation patterns of precipitation in Japan.

\section{Data and procedure of analysis}

The data used in this study are four-hourly precipitation records $(02,06, \ldots, 22$ JST) at JMA observatories from 1898 . The recently digitalized data were used for the period until 1975, and the AMeDAS (Automated Meteorological Data Acquisition System) data were used for 1976 to 2003.

As described by Fujibe et al. (2005c), the quality of the digitalized data is not perfect. After a rough quality check, they selected 46 stations which provided usable records for at least 80 years during the analysis period (1898-2003), including at least three years observation in the first five years (1898-1902). The same procedure was taken in the present study. Figure 1 shows the distribution of the stations used for analysis.

There is some inhomogeniety of observation units corresponding to changes of raingauge types. Until 1967, observation was made with conventional cylinder-type raingauges and siphon raingauges with resolution of $0.1 \mathrm{~mm}$. Since 1968, the tipping bucket raingauge has

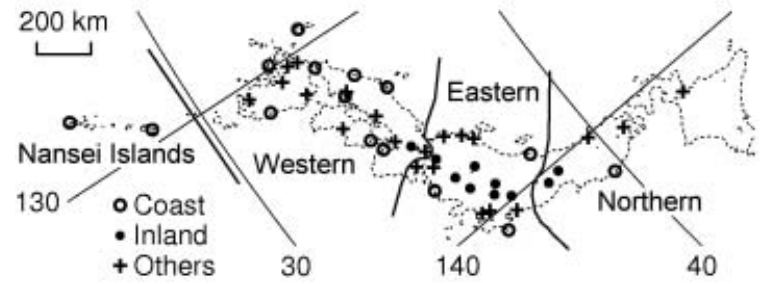

Fig. 1. Location of stations used for analysis. Coastal and inland stations are defined in Section 3.1.

been used with resolution of $0.5 \mathrm{~mm}$. The hourly AMeDAS data are recorded in the $1 \mathrm{~mm}$ resolution from 1976 to 1994 . In order to avoid the bias due to the differences in observation units, all the data were reduced to the resolution of $1 \mathrm{~mm}$. The tipping bucket raingauge incrementally measures the precipitation accumulation, so that precipitation of $4.3 \mathrm{~mm}$, for example, will be measured as $4 \mathrm{~mm}$ at the $70 \%$ probability, and $5 \mathrm{~mm}$ at the $30 \%$ probability in the observation of $1 \mathrm{~mm}$ resolution, depending on the initial water content in the bucket. Reduction to the $1 \mathrm{~mm}$ resolution was made by applying these probabilities as weights to the neighboring integer values. For example, a record of $4.3 \mathrm{~mm}$ was treated as a $4 \mathrm{~mm}$ record with a weight of 0.7 , and a $5 \mathrm{~mm}$ record with a weight of 0.3 .

The average precipitation amount for each time of the day in each year is obtained by

$$
P_{n j}=\sum_{i, m} p_{n m i j} / N_{n},
$$

where $p_{n m i j}$ is the precipitation amount at time $j$ at the station $i$ in the month $m$ in the year $n$, and $N_{n}$ is the number of items in the summation which covers the specified seasons and regions. The normalized precipitation, with respect to the daily mean is given by

$$
p_{n j}=P_{n j} /\left\langle P_{n}\right\rangle \text {, }
$$

where $\left\langle P_{n}\right\rangle$ is the average over $j$.

The linear trend of $p_{n j}$ is obtained from the least-squares condition

$$
\begin{aligned}
\sum_{n} & \left\langle P_{n}\right\rangle\left[p_{n j}-\left\{a_{j}+b_{j}\left(n-\frac{n_{1}+n_{2}}{2}\right)\right\}\right]^{2} \\
\rightarrow \text { min. } &
\end{aligned}
$$

where $n_{1}$ and $n_{2}$ are the first and the last year of the analysis period (namely, 1898 and 2003), 


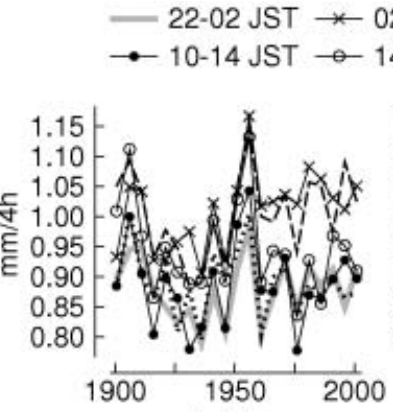

(a) $P_{n j}$
02-06 JST --- 06-10 JST

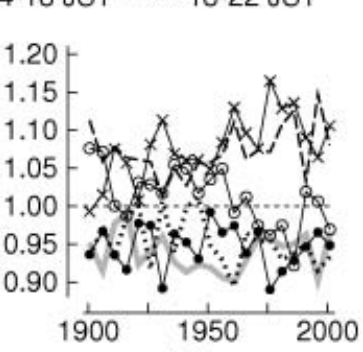

(b) prij
Fig. 2. Time series of (a) $P_{n j}$ and (b) $p_{n j}$ for March-August (five-year average) over the whole area.

and $a_{j}$ and $b_{j}$ are the least-squares coefficients indicating the long-term mean and the trend, respectively. The weight $\left\langle P_{n}\right\rangle$ was assigned in order to suppress the influence of some years in which precipitation is so scarce that the division in Eq. (2) becomes nearly singular, which can occur if the analysis is applied to a limited region and season. The confidence ranges of $a_{j}$ and $b_{j}$ were evaluated from the error matrix of the least-squares method. The procedure from Eq. (1) to Eq. (3) was also applied to the frequency of precipitation, which was categorized into intensity levels as described later in 3.2.

\section{Results}

\subsection{Precipitation amount}

Figure 2 shows the time series of $P_{n j}$ and $p_{n j}$ for spring and summer months, namely March-August, over the whole area (five-year average, except for six-year average for 18981903). The time series of $P_{n j}$ has considerable interannual variations, which largely mask the relative changes among the times of the day. The interannual variations are much reduced in the time series of $p_{n j}$, which indicates an increasing trend in the morning (02-06 and 06-10 JST) and a decreasing trend in the afternoon (14-18 JST).

Figure 3 shows the diurnal cycles of $P_{n j}$ and $p_{n j}$ for March-August in the first and last 25 years of the analysis period (1898-1922 and 1979-2003). The diurnal variation for 18981922 has conspicuous double maxima in 06-10 JST and 14-18 JST. In comparison, the 19792003 case has a more intense maximum at an earlier time in the morning, with only a faint

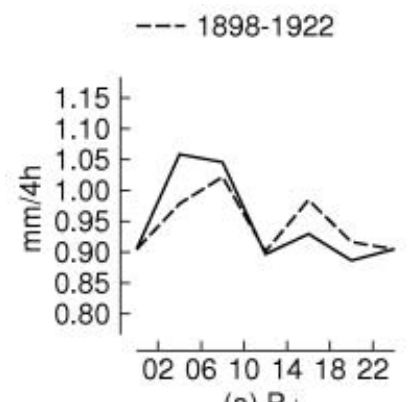

(a) $P_{n j}$
$1979-2003$

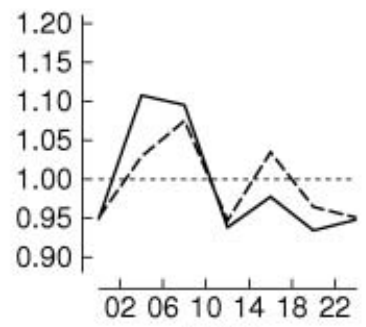

(b) $\mathrm{pnj}$
Fig. 3. Diurnal variation of (a) $P_{n j}$ and (b) $p_{n j}$ for March-August over the whole area in each 25-year period.

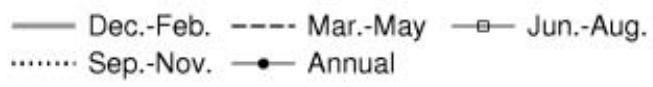

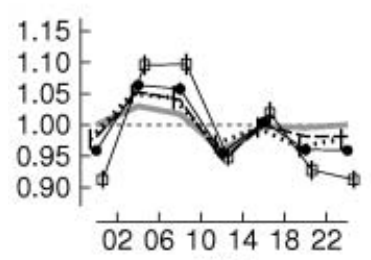

(a) $a_{j}$

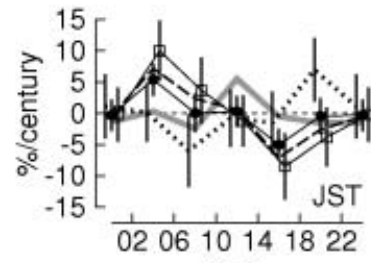

(b) $b_{j}$
Fig. 4. Diurnal variation of (a) $a_{j}$ and (b) $b_{j}$ defined in (3) for each season and the annual average. The $95 \%$ confidence ranges are shown in vertical bars for June-August, September-November, and the annual average. Some graphs have been shifted slightly to the right or left in order to avoid overlapping the error bars (in Figs. 5, 6 and 8 also).

maximum in the afternoon, corresponding to the increase in the morning and the decrease in the afternoon in Fig. 2.

Figure 4 shows the long-term mean and trend, namely $a_{j}$ and $b_{j}$ in (3), for each of the four seasons and the annual average. The diurnal variation of $a_{j}$ is common to all the seasons with respect to a primary maximum in the morning and a minimum in midday, aside from some differences for the evening. The trend $b_{j}$ has different features according to seasons. In spring and summer, a positive trend of 5-7\%/ century is found in the early morning (02-06 JST) and a negative trend of 5-8\%/century in the afternoon (14-18 JST). These trends are statistically significant at the 5\% level. In au- 


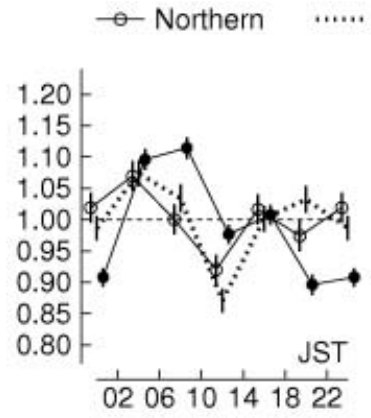

(a) $a_{j}$

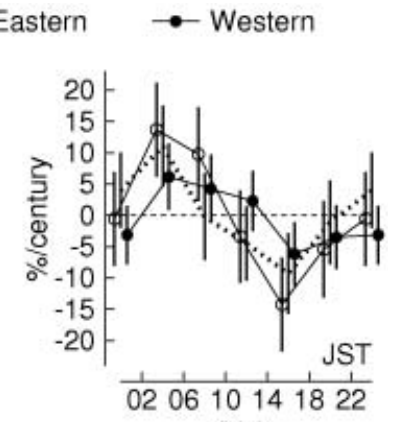

(b) bj
Fig. 5. Same as Fig. 4, but for each region for March-August.

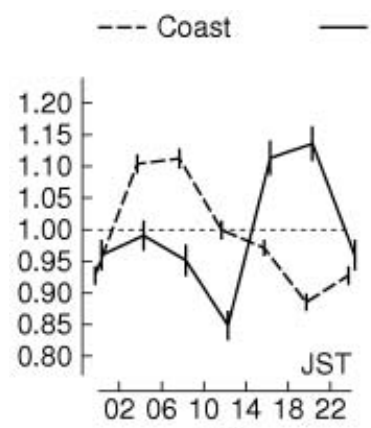

(a) $a_{j}$

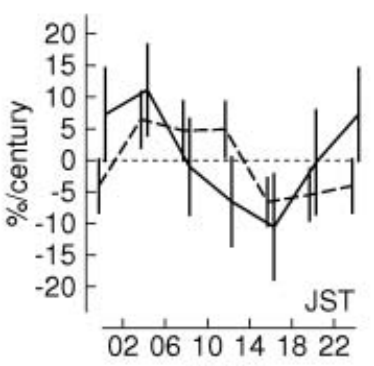

(b) $b_{j}$
Fig. 6. Same as Fig. 4, but for coastal and inland stations for March-August.

tumn, positive and negative trends are found in 18-22 JST and 06-10 JST, respectively. In winter there is a positive trend in midday. The trend on the annual mean reflects the feature of spring and summer, as a result of larger amount of precipitation in these seasons than others.

Figure 5 compares the three regions, except the Nansei Islands (Fig. 1), for March-August. The main features are common to the regions, including the positive and negative trends in 02-06 JST and 14-18 JST, respectively.

Figure 6 compares inland and coastal stations, which are defined on the basis of

$$
A=\frac{\iint \exp \left\{-\left(\frac{r}{r_{0}}\right)^{2}\right\} w(x, y) d x d y}{\iint \exp \left\{-\left(\frac{r}{r_{0}}\right)^{2}\right\} d x d y},
$$

where $x$ and $y$ are the eastward and northward coordinates centered on each station, $w(x, y)$

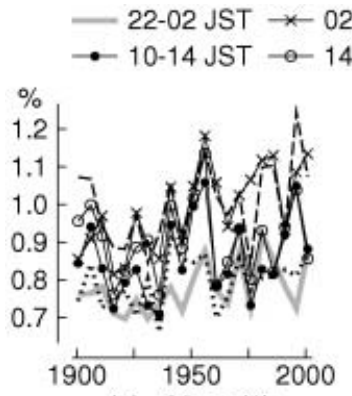

(a) $>20 \mathrm{~mm} / 4 \mathrm{~h}$ (b) $1-2 \mathrm{~mm} / 4 \mathrm{~h}$

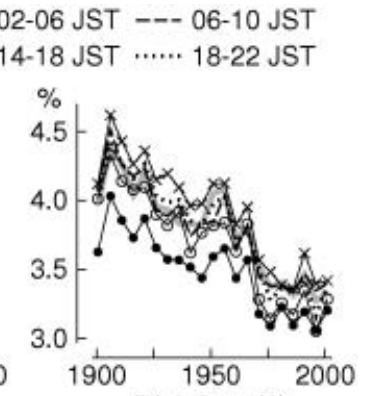

Fig. 7. Time series of the frequency of (a) $\geqq 20 \mathrm{~mm} / 4 \mathrm{~h}$ and (b) $1-2 \mathrm{~mm} / 4 \mathrm{~h}$ precipitation (five-year average over the whole area).

$=1$ if the point $(x, y)$ is land and $w(x, y)=0$ otherwise, $r^{2}=x^{2}+y^{2}$, and $r_{0}=25 \mathrm{~km}$. An inland station is defined by $A \geqq 0.95$, and a coastal station by $A<0.6$ (see Fig. 1). The numbers of inland and coastal stations are 10 and 15 , respectively. The diurnal variation of $a_{j}$ has opposite phases between coastal and inland stations, with maxima in the morning and evening, respectively. However, a positive trend in the morning and a negative trend in the afternoon are common to the two groups, aside from some differences in midday and midnight.

\subsection{Precipitation frequency for different intensity levels}

Figure 7 shows the time series of the frequency of $\geqq 20 \mathrm{~mm} / 4 \mathrm{~h}$ precipitation and 1 $2 \mathrm{~mm} / 4 \mathrm{~h}$ precipitation for the average over each five-year period. The $\geqq 20 \mathrm{~mm} / 4 \mathrm{~h}$ precipitation, which accounts for about $1 \%$ of the whole cases, shows an increasing trend of $12 \% /$ century superimposed on interannual variations. In contrast, the $1-2 \mathrm{~mm} / 4 \mathrm{~h}$ frequency has a conspicuous decreasing trend of $-27 \%$ century for all the times of the day. This differential change agrees with the analysis of Fujibe et al. (2005c). In fact, the frequency of $\geqq 50 \mathrm{~mm} / 4 \mathrm{~h}$ cases has an increasing trend of as large as $27 \% / c e n t u r y$, although the sample population is too small to detect the change in the diurnal variation pattern with sufficient reliability.

Figure 8 shows the diurnal cycles of $\geqq 20 \mathrm{~mm} / 4 \mathrm{~h}$ and $1-2 \mathrm{~mm} / 4 \mathrm{~h}$ frequency in the first and the last 25 years of the analysis period. The increase of $\geqq 20 \mathrm{~mm} / 4 \mathrm{~h}$ precipitation 


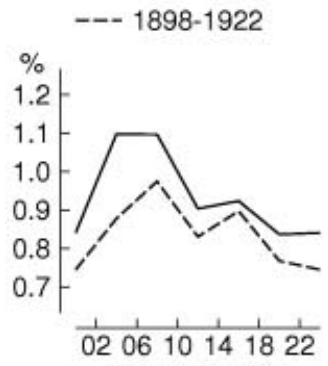

(a) $>20 \mathrm{~mm} / 4 \mathrm{~h}$

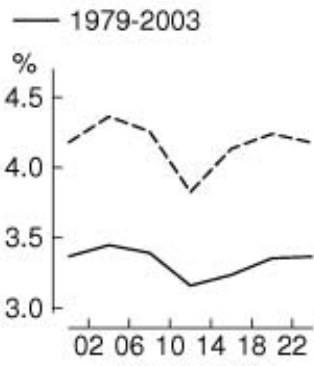

(b) $1-2 \mathrm{~mm} / 4 \mathrm{~h}$
Fig. 8. Diurnal variation of (a) $\geqq 20 \mathrm{~mm} /$ 4h and (b) 1-2 $\mathrm{mm} / 4 \mathrm{~h}$ precipitation (whole area) in each 25-year period.

and the decrease of $1-2 \mathrm{~mm} / 4 \mathrm{~h}$ precipitation are evident, while there are slight changes in the diurnal variation patterns. Hereafter we focus on the normalized diurnal variation with respect to the daily mean, corresponding to $p_{n j}$, $a_{j}$, and $b_{j}$ defined in Section 2. The notations $a_{j}$ and $b_{j}$ are used in common.

Dec.-Feb. ---- Mar.-May $\quad-$ Jun.-Aug.
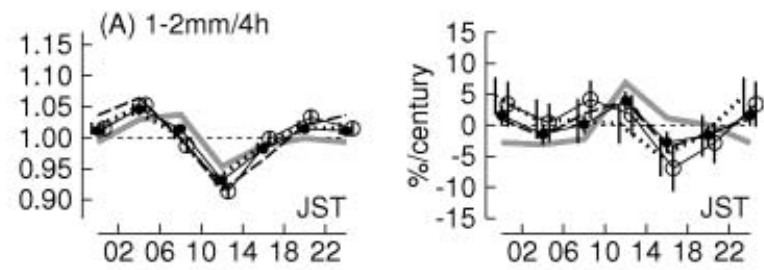

(C) $3-5 \mathrm{~mm} / 4 \mathrm{~h}$

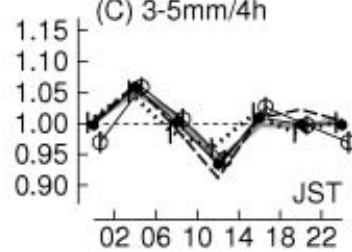

(E) $10-20 \mathrm{~mm} / 4 \mathrm{~h}$

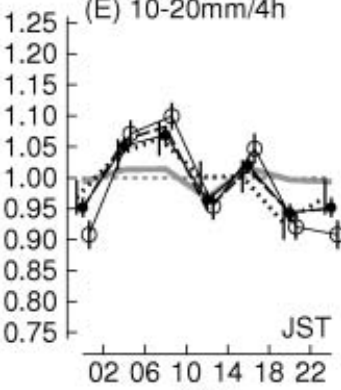

(a) $a_{j}$
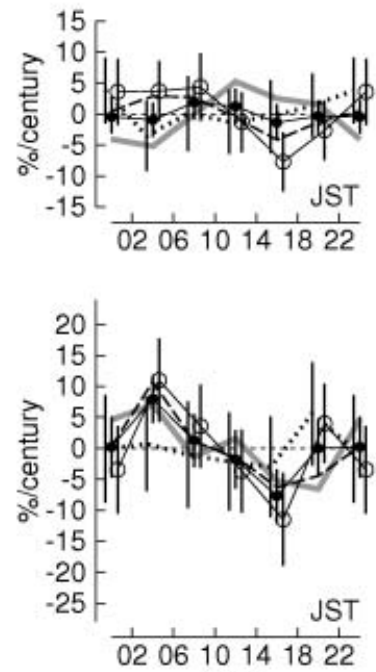

(b) $b_{j}$
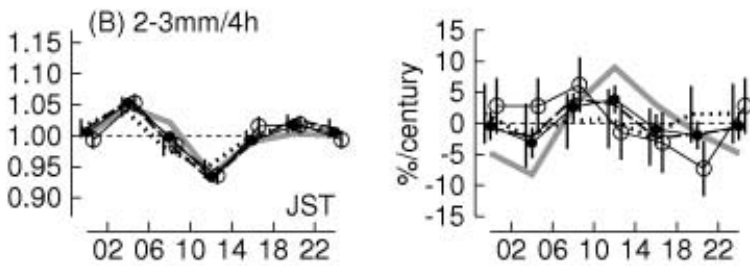

(D) $5-10 \mathrm{~mm} / 4 \mathrm{~h}$
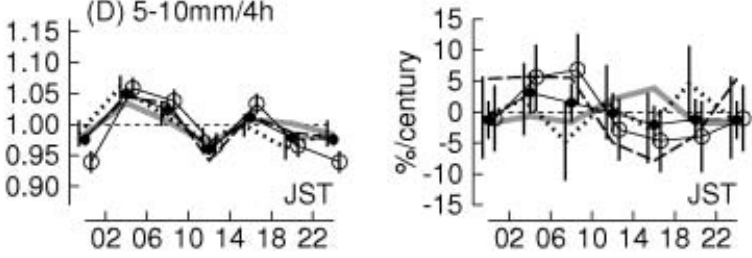

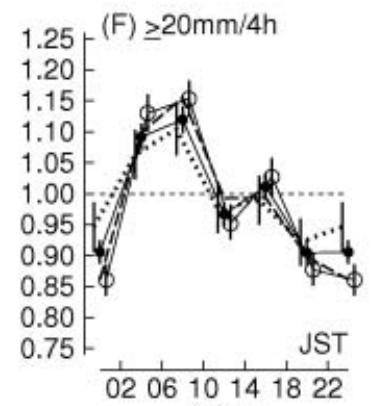

(a) $a_{j}$

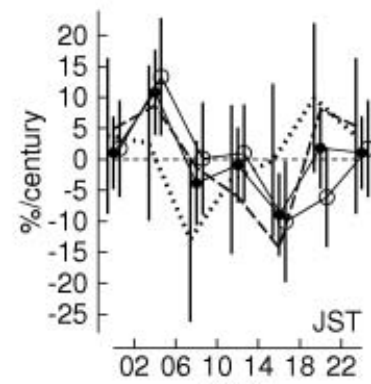

(b) b

Fig. 9. Same as Fig. 4, but for precipitation frequency in each intensity range. 


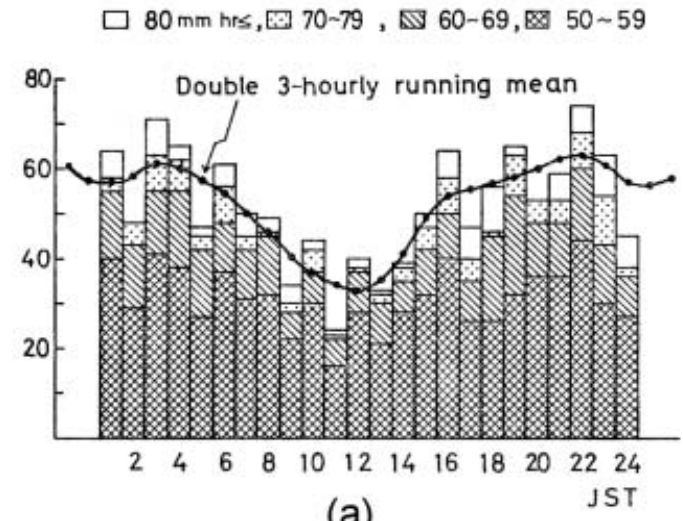

(a)

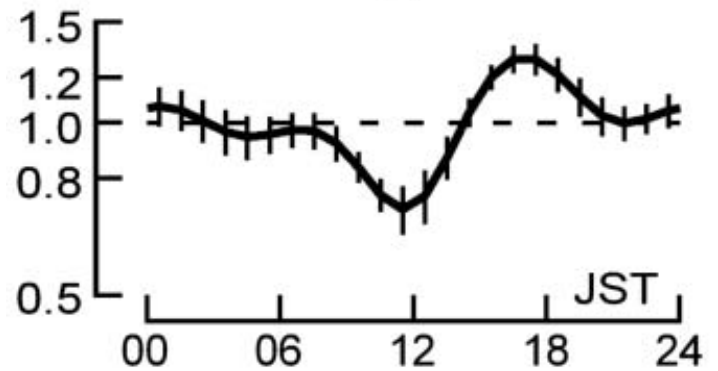

(b)

Fig. 10. Diurnal variation of the frequency of $50 \mathrm{~mm} / \mathrm{h}$ precipitation obtained for (a) 1955-1965 (Yasuda 1970), and (b) 1979-1996 (Fujibe 1999). The $y$-axis in (a) indicates the total number of cases over the stations (about 1000 in number). That in (b) gives relative frequency with the daily average as unity.

\section{Summary and remarks}

The main feature of our results is a relative increasing trend of precipitation amount in early morning (02-06 JST) and a decreasing trend in the afternoon (14-18 JST), with a rate of about 5\% per century. These changes reflect those of intense precipitation $(\gtrsim 10 \mathrm{~mm} / 4 \mathrm{~h})$ in spring and summer. This feature is in qualitative agreement with the decrease of thunder frequency in summer in the recent 42 years (Fujibe et al. 2005b). However, the decreasing rate of thunder frequency is as large as 10\%/ decade, which is an order of magnitude larger than those of precipitation amount and the frequency of intense precipitation in our analysis. It can be seen in Figs. 2 and 7 that there are variations on the scale of several decades superimposed on linear trends. It is therefore possible that the trend evaluated by Fujibe et al. (2005b) is overestimated by such multidecadal variations, which should be canceled out if the data have sufficient time span. Another possibility is the difference of the climatological features of precipitation and thunderstorms. Indeed, the summer thunder frequency has decreased rapidly during the later half of the 20th century (Kitagawa 1989; Yoshida 2002), in spite of the increasing trend of intense precipitation (Fujibe et al. 2005c). This fact suggests that there can be some difference in longterm changes in the diurnal variation patterns of precipitation and thunderstorms.

For weaker precipitation, long-term changes of diurnal cycles are generally small, with different time-of-the-day dependence from that of intense precipitation. Precipitation of the lowest two categories $(1-2 \mathrm{~mm} / 4 \mathrm{~h}$ and $2-3 \mathrm{~mm} /$ 4h) shows a slight relative increase in 06-14 JST and a decrease in 14-18 JST. On the other hand, the precipitation frequency based on visual observation for 1961-2002 shows relative increase in the nighttime with a rate of several percent per decade (Fujibe et al. 2005a). Since visual observation covers very weak precipitation undetectable with raingauges, their result implies differential changes between very weak $(<1 \mathrm{~mm} / 4 \mathrm{~h})$ and moderately weak $(1-3 \mathrm{~mm} / 4 \mathrm{~h})$ precipitations.

So far there is only a little information on the changes of diurnal precipitation cycles in other regions of the world. The analysis of Dai (1999) for the contiguous United States during 19631993 shows an increase of summer afternoon precipitation over many regions and a decrease in some areas. This result seems to imply largescale variability in the change of diurnal precipitation cycles. On the other hand, the analysis of Jung et al. (2001) for 220-year records at Seoul shows different diurnal patterns between the dry period in 1884-1910 and the remaining periods, implying the possibility of changes of the centennial time scale. It is a problem of future studies to find the relationship between our result and the global climate change over a hundred years or more.

Finally a brief comment is made on very intense precipitation, which is out of the range of the present paper, due to lack of sample size large enough to achieve a statistically reliable 
result. Figure 10 compares the diurnal variation of the frequency of $\geqq 50 \mathrm{~mm} / \mathrm{h}$ precipitation obtained by Yasuda (1970) for 1955-1965, and Fujibe (1999) for 1979-1996. The two studies are based on much denser networks than ours, with nearly 1000 raingauges over Japan, except the Nansei Islands. The network was renewed at the deployment of the AMeDAS system in the 1970's. The two results agree with respect to the midday minimum, but the late afternoon maximum for 1979-1996 is lacking in the diurnal variation for 1955-1965. This difference implies a possibility of an increase of very intense precipitation in the late afternoon, in contrast to the decrease of $20 \mathrm{~mm} / 4 \mathrm{~h}$ precipitation in our result. The longterm change in the diurnal cycle of extremely intense precipitation is another problem for future research.

\section{References}

Changnon, S.A. Jr. ed., 1981: METROMEX: A review and summary. Meteor. Monogr., 40, Amer. Meteor. Soc., 181pp.

Dai, A., 1999: Recent changes in the diurnal cycle of precipitation over the United States. Geophys. Res. Lett., 26, 341-344.

_ 2001 : Global precipitation and thunderstorm frequencies. Part II: Diurnal variations. J. Climate, 14, 1112-1128.

Fujibe, F., 1988: Diurnal variation of precipitation and thunderstorm frequency in Japan in the warm season. Pap. Meteor. Geophys., 39, 7994.

, 1998: Spatial anomalies and long-term changes of precipitation in Tokyo. Tenki, 45, 7-18 (in Japanese with English abstract).

, 1999: Diurnal variation in the frequency of heavy precipitation in Japan. J. Meteor. Soc. Japan, 77, 1137-1149.

, N. Yamazaki, and M. Katsuyama, 2005a: Long-term trends in the diurnal cycles of precipitation frequency in Japan. Pap. Meteor. Geophys., 55, 13-19.

, — , and 2005b: Long-term trends in the diurnal cycles of thunder frequency in Japan. Tenki, 52, 235-239 (in Japanese with English abstract).

and K. Kobayashi, 2005c: The increasing trend of intense precipitation in Japan based on four-hourly data for a hundred years. SOLA, 1, 41-44, doi: 10.2151/sola.2005012.

Hirose, M. and K. Nakamura, 2005: Spatial and diurnal variation of precipitation systems over Asia observed by the TRMM Precipitation Radar. J. Geophys. Res., 110, D05106, doi:10.1029/2004JD004815.

$\mathrm{Hu}$, Q., 2003: A multidecadal variation in summer season diurnal rainfall in the central United States. J. Climate, 16, 174-178.

Jung, H.-S., G.-H. Lim, and J.-H. Oh, 2001: Interpretation of the transient variations in the time series of precipitation amounts of Seoul: Part I. Diurnal variation. J. Climate, 14, 29893004.

Kitagawa, N., 1989: Long-term variations in thunder-day frequencies in Japan. J. Geophys. Res., D94, 13183-13189.

Landsberg, H.E., 1981: The urban climate. Academic Press, 275pp.

Misumi, Y., 1999: Diurnal variations of precipitation grouped into cloud categories around the Japanese archipelago in the warm season. J. Meteor. Soc. Japan, 77, 615-635.

Mohr, K.I., 2004: Interannual, monthly, and regional variability in the wet season diurnal cycle of precipitation in sub-Saharan Africa. J. Climate, 17, 2441-2453.

Oki, T. and K. Musiake, 1994: Seasonal change of the diurnal cycle of precipitation over Japan and Malaysia. J. Appl. Meteor., 33, 1445-1463.

Shinoda, M., T. Okatani, and M. Saloum, 1999: Diurnal variations of rainfall over Niger in the West Africa Sahel: A comparison between wet and drought years. Int. J. Climatol., 19, 81-94.

Tagami, Y., 1990: Diurnal variation of precipitation frequency in the Japanese Islands. Geogr. Rev. Japan, 63A, 407-430 (in Japanese with English abstract).

Tsakraklides, G. and J. Evans, 2003: Global and regional diurnal variations of organized convection. J. Climate, 16, 1562-1572.

Yasuda, K., 1970: Climatological features of the heavy rainfall intensity (above $50 \mathrm{~mm} / \mathrm{hr}$ ) in Japan. Tenki, 17, 539-548 (in Japanese).

Yoshida, H., 2002: Geographical distributions and long-term variations of thunder-day frequencies in Japan. Tenki, 49, 279-285 (in Japanese). 